University of Wollongong

Research Online

Australian Institute for Innovative Materials -

Papers

Australian Institute for Innovative Materials

$1-1-2019$

Synthesis of CoSe2-SnSe2 nanocube-coated nitrogen-doped carbon (NC) as anode for lithium and sodium ion batteries

Jin Bai

Hubei University

Huimin Wu

Hubei University, hw267@uow.edu.au

Shiquan Wang

Hubei University

Guangxue Zhang

Hubei University of Science and Technology

Chuanqi Feng

Hubei University,Hubei University of Science and Technology, cfeng@hubu.edu.cn

See next page for additional authors

Follow this and additional works at: https://ro.uow.edu.au/aiimpapers

Part of the Engineering Commons, and the Physical Sciences and Mathematics Commons

Research Online is the open access institutional repository for the University of Wollongong. For further information contact the UOW Library: research-pubs@uow.edu.au 


\title{
Synthesis of CoSe2-SnSe2 nanocube-coated nitrogen-doped carbon (NC) as anode for lithium and sodium ion batteries
}

\author{
Abstract \\ CoSe2-SnSe2/NC nanocubes (CSNC@NC) coated by nitrogen-doped carbon (NC) were synthesized \\ successfully by an ordinary pyrazole polymerization and carbonization process. In comparison with bare \\ CSNC, the CSNC@NC composite exhibited good structural stability and improved electrical conductivity \\ when used as anode. The CSNC@NC electrode showed a stable Li storage capacity (730.41 mAh g-1 \\ over 100 cycles at $0.2 \mathrm{Ag}-1)$ and excellent rate performance ( $402.10 \mathrm{mAh} \mathrm{g}-1$ at $2 \mathrm{~A} \mathrm{~g}-1)$. For $\mathrm{Na}$ \\ storage, the discharge capacity could be maintained 279.3 mAh g-1 over 100 cycles at $0.2 \mathrm{~A} \mathrm{~g}-1$; the \\ lower capacity than that for $\mathrm{Li}$ storage maybe caused by the larger size of $\mathrm{Na}+$ ions. The excellent cycling \\ stability for both $\mathrm{Li}$ and $\mathrm{Na}$ storage cycle ability may be attributed to the carbon layer, which could \\ tolerated the volume fluctuations and ensured the structural integrity of the CSNC during the charge/ \\ discharge process; Moreover, the improved electrical conductivity accelerated the diffusion rate of both \\ $\mathrm{Li}+$ and $\mathrm{Na}+$, which is conducive to the electrochemical reactions in their respective batteries. This unique \\ structure and preeminent electrochemical performance of CSNC@NC show that CSNC@NC is a \\ promising anode material for high-efficiency Li ion and $\mathrm{Na}$ ion batteries.
}

\section{Keywords}

cose2-snse2, synthesis, nanocube-coated, nitrogen-doped, ion, carbon, batteries, (nc), anode, lithium, sodium

\section{Disciplines}

Engineering | Physical Sciences and Mathematics

\section{Publication Details}

Bai, J., Wu, H., Wang, S., Zhang, G., Feng, C. \& Liu, H. (2019). Synthesis of CoSe2-SnSe2 nanocube-coated nitrogen-doped carbon (NC) as anode for lithium and sodium ion batteries. Applied Surface Science, 488 512-521.

\section{Authors}

Jin Bai, Huimin Wu, Shiquan Wang, Guangxue Zhang, Chuanqi Feng, and Hua-Kun Liu 


\title{
Synthesis of $\mathrm{CoSe}_{2}-\mathrm{SnSe}_{2}$ nanocube-coated nitrogen-doped carbon (NC) as anode for lithium and sodium ion batteries
}

Jin Bai ${ }^{\mathbf{a}}$, HuiminWu ${ }^{\mathbf{a}}$, ShiquanWanga, Guangxue Zhang ${ }^{\mathbf{b} *}$, Chuanqi Fenga,b*, HuakunLiu ${ }^{\mathbf{c}}$

${ }^{\text {a}}$ Hubei Collaborative Innovation Center for Advanced Organic Chemical Materials and Ministry of Education Key Laboratory for the Synthesis and Applications of Organic Functional Molecules, Hubei University, Wuhan, 430062, China

b School of Nuclear Technology and Chemistry \& Biology, Hubei University of Science and Technology, Xianning 437100, China

${ }^{\mathbf{c}}$ Institute for Superconducting and Electronic Materials, University of Wollongong, Wollongong, NSW 2522, Australia

\begin{abstract}
$\mathrm{CoSe}_{2}-\mathrm{SnSe}_{2}$ nanocubes /NC (CSNC@NC) coated by nitrogen-doped carbon (NC) were synthesized successfully by an ordinary pyrazole polymerization and carbonization process. By comparison with bare $\mathrm{CoSe}_{2}-\mathrm{SnSe}_{2}$ nanocubes (CSNC), the CSNC@NC composite exhibited good structural stability and improved electrical conductivity when used as anode. The CSNC@NC electrode showed a stable Li storage capacity $\left(730.41 \mathrm{mAh} \mathrm{g}^{-1}\right.$ over 100 cycles at $\left.0.2 \mathrm{~A} \mathrm{~g}^{-1}\right)$ and excellent rate performance (402.10 $\mathrm{mAh} \mathrm{g}^{-1}$ at $2 \mathrm{~A} \mathrm{~g}^{-1}$ ). For Na storage, the discharge capacity could be maintained at $279.3 \mathrm{mAh} \mathrm{g}^{-1}$ over 100 cycles when current density was $0.2 \mathrm{Ag}^{-1}$; the lower capacity than that of CSNC for Li storage maybe caused by the larger size of $\mathrm{Na}^{+}$ions. The excellent cycling stability for both $\mathrm{Li}^{+}$and $\mathrm{Na}^{+}$storage may be attributed to the carbon layer, which could tolerated the volume fluctuations and ensured the structural integrity of the CSNC during the charge/discharge process; Moreover, the improved electrical
\end{abstract}


conductivity accelerated the diffusion rate of both $\mathrm{Li}^{+}$and $\mathrm{Na}^{+}$, which is conducive to the electrochemical reactions in their respective batteries. This unique structure and preeminent electrochemical performance of CSNC@NC show that CSNC@NC is a promising anode material for high-efficiency $\mathrm{Li}$ ion and $\mathrm{Na}$ ion batteries.

Keywords: Transition metal selenides; Li ion battery; $\mathrm{Na}$ ion battery; Electrochemical performance.

\section{Introduction}

In recent years, sustainability and the storage of renewable energy have been the main direction of development in the energy storage field. Lithium ion batteries (LIBs) evolved as the backbone of energy storage devices under these conditions [1-3],owing to their high energy density, light weight and long cycle life, so that LIBs have been used extensively in portable electronic equipment and electric vehicles [47].Nevertheless, the cost and limited nature of lithium resources have limited the wider development of LIBs [8, 9]. Recently, sodium ion batteries (SIBs) have attracted extensive attention due to the similar working principles of SIBs and LIBs, while sodium has more abundant resources and lower economic costs, which is promising for large-scale energy storage [10-14]. Unfortunately, the radius of the $\mathrm{Na}^{+}$ion is $1.02 \AA$, while that of the $\mathrm{Li}^{+}$ion is $0.76 \AA$ [15-17], so the larger size of the $\mathrm{Na}^{+}$ion means that some anode materials for LIBs, such as graphite, cannot achieve the desired effect when serving as anode for SIBs $[18,19]$. Therefore, searching for promising anode materials with greater capacity and excellent stability for both LIBs and SIBs is indispensable for the development of battery technologies. Transition metal dichalcogenides (TMDs) have attracted considerable attention for LIBs, SIBs and so on, due to their high theoretical capacity and excellent electrochemical performances [20-22].These materials, including $\mathrm{CoSe}_{2}[23], \mathrm{MoSe}_{2}[24], \mathrm{NiSe}_{2}[25]$, and $\mathrm{WS}_{2}[26]$, have demonstrated high capacity and long-term durability for both lithium and sodium storage. Recently, $\mathrm{CoSe}_{2}-\mathrm{SnSe}_{2}$ nanocube (CSNC) hybrids with rich nano-/mesopores have been successfully synthesized. This hybrid of two different metal chalcogenides 
exhibits superior performance when used as hydrogen evolution (HER) catalysts on account of its abundant and accessible active sites arising from both metal chalcogenides components $[27,28]$. Its unique structure and characteristics make CSNC be a desirable material for battery technology.

When used as anode for LIBs, the theoretical capacities of $\mathrm{CoSe}_{2}$ and $\mathrm{SnSe}_{2}$ are $494.44 \mathrm{mAh} \mathrm{g}^{-1}$ and $813 \mathrm{mAh} \mathrm{g}^{-1}$ (Alloy: $426 \mathrm{mAh} \mathrm{g}^{-1}$, Conversion: $387 \mathrm{mAh} \mathrm{g}^{-1}$ ), respectively. Therefore, high theoretical capacity makes $\mathrm{CoSe}_{2}-\mathrm{SnSe}_{2}$ composite be used as a viable anode in LIBs. Nevertheless, none of the research focuses on the synthesis and electrochemical performance testing of $\mathrm{CoSe}_{2}-\mathrm{SnSe}_{2}$ composite in the lithium ion battery field at present, so the study on $\mathrm{CoSe}_{2}-\mathrm{SnSe}_{2}$ composite as anode for LIBs is meaningful work.

Currently, in order to enable superior Li and $\mathrm{Na}$ storage performance, one major obstacle for CSNC that needs to be solved is its huge volume changes during cycling. This phenomenon, occurring frequently among the TMDs anode materials, means that the cycling performance is disappointing [29, 30]. Many measures have been tried to alleviate this problem, and the more common options involve combinations of highly conductive carbonaceous materials and TMDs, for example, sheet-like $\mathrm{MoSe}_{2} / \mathrm{C}$ composites [31], $\mathrm{FeSe}_{2}$-amorphous carbon composite[32], $\alpha-\mathrm{MnS}$ decorated on N,S and Co doped nanotube-like carbon [33], and $\mathrm{SnS}_{2}$-graphene hybrids [34]. Among them, surface carbon coating has been proven to be a feasible method, not because of low economic cost, but because the carbon coating can also acts as an elastic protecting and electrically conducting layer. In this case, the problem of volumetric expansion will be solved, and its electrochemical properties could be improved.

In this study, $\mathrm{CoSe}_{2}-\mathrm{SnSe}_{2}$ nanocubes were synthesized via an ordinary aqueous reaction and selenization process as the precursor, and then, after passing through a pyrrole polymerization and carbonization processes, nitrogen-doped carbon (NC) coated $\mathrm{CoSe}_{2}-\mathrm{SnSe}_{2}$ nanocube (CSNC@NC) was successfully prepared. The unique structures with their conductive and protective carbon layer ensure the structural integrity of CSNC@NC and mean that it can demonstrate excellent electrochemical performance for $\mathrm{Li}$ and $\mathrm{Na}$ storage. 


\section{Experimental}

\subsection{Synthesis of $\mathrm{CoSn}(\mathrm{OH})_{6}$}

Firstly, in order to synthesize $\mathrm{CoSn}(\mathrm{OH})_{6}$ nanocubes, 4 mmol $\mathrm{Na}_{3} \mathrm{C}_{6} \mathrm{H}_{5} \mathrm{O}_{7} \cdot 2 \mathrm{H}_{2} \mathrm{O}$ and $4 \mathrm{mmol} \mathrm{CoCl}_{2} \cdot 6 \mathrm{H}_{2} \mathrm{O}$ were dissolved in $140 \mathrm{ml}$ deionized water at room temperature. Next $4 \mathrm{mmol} \mathrm{SnCl}_{4} \cdot 5 \mathrm{H}_{2} \mathrm{O}$ dissolved in $20 \mathrm{ml}$ ethanol was prepared and added to the above solution under magnetic stirring. $20 \mathrm{ml} \mathrm{NaOH}(2 \mathrm{M})$ solution was then added drop by drop, and the obtained solution was kept under stirring for $12 \mathrm{~h}$. The final product was collected by filtration, washed several times with deionized water, and freeze-dried for $24 \mathrm{~h}$. $\mathrm{CoSn}(\mathrm{OH})_{6}$ nanocubes were next added into $120 \mathrm{ml}$ deionized water with $0.32 \mathrm{~mol} \mathrm{NaOH}$ and subjected to magnetic stirring for $10 \mathrm{~min}$ for etch the materials. The precipitate was collected by centrifugation with deionized water and freeze-dried for $24 \mathrm{~h}$.

\subsection{Synthesis of CSNC}

$130 \mathrm{mg}$ selenium powder and $180 \mathrm{mg} \mathrm{CoSn}(\mathrm{OH})_{6}$ nanocubes were mixed uniformly in an ball-milling jar, and then the gray powder was heated to $300{ }^{\circ} \mathrm{C}$ for $6 \mathrm{~h}$ in argon atmosphere. The final product was $\mathrm{CoSe}_{2}-\mathrm{SnSe}_{2}$ nanocubes.

\subsection{Synthesis of CSNC@NC}

$100 \mathrm{mg}$ as-synthesized CSNC was ultrasonically dispersed in $40 \mathrm{ml}$ deionized water for $1 \mathrm{~h}$. Then, the obtained solution was stirred in an ice-water bath for $20 \mathrm{~min}$. $80 \mu 1$ pyrrole monomer was dripped into the mixture with a fin pipette and followed by the dropwise addition of ready-prepared $\left(\mathrm{NH}_{4}\right)_{2} \mathrm{~S}_{2} \mathrm{O}_{8}$ solution. After stirring for $6 \mathrm{~h}$ in the ice-water bath, the precipitate was collected by filtration with deionized water and dried at $80^{\circ} \mathrm{C}$ for $6 \mathrm{~h}$ in a vacuum oven. The carbonization processes was performed at $400{ }^{\circ} \mathrm{C}$ for $2 \mathrm{~h}$ in Ar atmosphere. The CSNC@NC-(1, 2, 3) samples were marked according to the different added amounts of pyrrole monomer $(40 \mu 1,80 \mu 1,140 \mu 1)$.

\subsection{Materials characterization}

Samples were characterized by X-ray powder diffraction (XRD, Bruker D8 Advance) and X-ray photoelectron spectroscopy (XPS, Escalab 250Xi). The morphology and microstructure were observed by scanning electron microscopy (SEM, JEOLJSM 6510V), transmission electron microscopy (TEM, Tecnai G20 U-Twin), and 
Raman spectroscopy (Jobin-Yvon HR800). The mass ratio was confirmed by thermogravimetric analysis (TGA).

\subsection{Electrochemical measurements}

The electrochemical properties were tested after assembled into 2025-type coincells in a glove box. Working electrodes were prepared by mixing the active material (70wt.\%), acetylene black (20 wt.\%), and poly(vinylidenefluoride) (PVDF) binder (10 wt.\%). The slurry was uniformly smeared on copper foil, then dried at $100^{\circ} \mathrm{C}$ for $10 \mathrm{~h}$ in a vacuum oven. Lithium tablets was used as counter electrode, and $1 \mathrm{~mol} \cdot \mathrm{L}^{-}$ ${ }^{1} \mathrm{LiPF}_{6}$ in ethylene carbonate/dimethylcarbonate (EC: DMC $=1: 1$ by volume) was chosen as electrolyte for the Li half-cells. The Na half-cells had the same assembly process, except that sodium metal was used for the counter electrode with a different separator (glass fiber), and the electrolyte was $(1 \mathrm{M} \mathrm{NaClO} 4$ in ethylene carbonate $(\mathrm{EC}) /$ dimethyl carbonate $(\mathrm{DEC})$ in a 1:1 volume ratio $+5 \%$ fluoroethylene carbonate (FEC)). The cycling and rate performance was assessed using a LAND battery test system. Cyclic voltammetry (CV) and electrochemical impedance spectroscopy (EIS) were conducted on an electrochemical work station (CHI-600E).

\section{Results and discussion}

\subsection{Structure and morphology of samples}

The structures of CSNC and CSNC@NC were examined by XRD (Fig. 1). The XRD pattern of $\mathrm{CoSn}(\mathrm{OH})_{6}$ is shown in Fig.1a. It is obvious that the identified diffraction peaks of $\mathrm{CoSn}(\mathrm{OH})_{6}$ can match well with cubic $\mathrm{CoSn}(\mathrm{OH})_{6}$ phase (PDF\#130356). Fig.1b shows the XRD patterns of CSNC and CSNC@NC-(1, 2, 3), and the identified diffraction peaks of CSNC and CSNC@NC-(1,2,3) marked with corresponding to indices of crystallographic plane (200), (210), (211), (220), (311), (222), (230), (321) and (400) of cubic $\mathrm{CoSe}_{2}$ phase (c-CoSe $\left.2, \mathrm{PDF} \# 09-0234\right)$, respectively. the identified diffraction peaks marked with $\diamond$, corresponding to indices of crystallographic plane (110),(111), (012), (121), (211) and (220) of orthorhombic $\mathrm{CoSe}_{2}$ phase(o-CoSe $\left.2, \mathrm{PDF} \# 10-0408\right)$, respectively. The characteristic peaks marked 
with

, corresponding to indices of crystallographic plane (0027), (110), (119), (0036) and (1127) of hexagonal $\mathrm{SnSe}_{2}$ phase (PDF\#40-1465), respectively. Besides, a few impurity peaks occurred due to the excessive selenium powder exists in CSNC@NC and resulted in some other peaks shift. There is an additional peak that occurs at around $26.5^{\circ}$ in CSNC@NC- $(1,2,3)$, which can be explained as due to the presence of carbon, and the peak intensity increase with carbon content.

The Raman spectra of CSNC and CSNC@NC-(1,2,3) are shown in Fig. 2a. There are two peaks located at 1350 and $1580 \mathrm{~cm}^{-1}$, which imply the presence of defectinduced carbon (D-band) and graphitic carbon (G-band), respectively, while, no peaks appear in CSNC, suggesting that the carbon is only present in the CSNC@NC-(1,2,3). In order to analyze the exact amount of carbon, TGA was carried out, and the TGA curves are shown in Fig. 2b. It is clear that when the curves become stable after $700^{\circ} \mathrm{C}$, the remaining weight percentage of CSNC, CSNC@NC-1, CSNC@NC-2, and CSNC@NC-3 is $58.76 \%, 41.20 \%, 36.24 \%$ and $22.19 \%$, respectively. This demonstrates that the carbon contents of CSNC@NC-1, CSNC@NC-2, and CSNC@NC-3 are 17.56\%, 22.51\% and 36.57\%, respectively.

XPS was used to detect the elements and their valence states of CSNC@NC (Fig. 3). The survey spectrum in Fig. 3a verifies the presence of the elements Se, C, N, Sn, and Co. The Se 3d spectrum is shown in Fig. 3b, where the peak at $54.79 \mathrm{eV}$ corresponds to $\mathrm{Se}^{2-}$ and $\mathrm{Se}_{2}{ }^{2-}$ in $\mathrm{SnSe}_{2}$ and $\mathrm{CoSe}_{2}[35,36]$. Another peak at $58.78 \mathrm{eV}$ can be attributed to the presence of $\mathrm{SeO}_{x}$, which has been intensively investigated in previous reports [37]. There are four peaks that occur in the Co $2 p$ spectrum (Fig. 3c): the peaks located at 780.90 and $797.10 \mathrm{eV}$ can be interpreted as the peaks for Co $2 \mathrm{p}_{3 / 2}$ and Co $2 \mathrm{p}_{1 / 2}$, respectively, which imply the existence of $\mathrm{Co}^{2+}$ in $\mathrm{CoSe}_{2}$, and two additional satellite peaks appear around the Co $2 p$ peaks. The $\operatorname{Sn} 3 \mathrm{~d}_{5 / 2}$ and $\mathrm{Sn} 3 \mathrm{~d}_{3 / 2}$ peaks (Fig.3d) appear at 487.08 and $495.58 \mathrm{eV}$, respectively, suggesting that the main valence state of stannum $(\mathrm{Sn})$ is $\mathrm{Sn}^{4+}$. The $\mathrm{C} 1 \mathrm{~s}$ spectrum is shown in Fig.3e, and displays three different peaks at 284.80, 285.78 and $289.22 \mathrm{eV}$, which can interpreted as $\mathrm{C}-\mathrm{C}, \mathrm{C}-\mathrm{N}$, and $\mathrm{C}=\mathrm{O}$, respectively. Fig. $3 \mathrm{f}$ shows the $\mathrm{N}$ 1s spectrum at higher energy. It exhibits pyridinic, pyrrolic/pyridine and quaternary nitrogen peaks with binding 
energy of 398.20, 400.00 and $401.40 \mathrm{eV}$, respectively. The existence of nitrogen in the carbon layer could have some good effects on lithium ion penetration into the electrode materials.

The morphologies of $\mathrm{CoSn}(\mathrm{OH})_{6}, \mathrm{CSNC}$, and CSNC@NC-2 were observed by SEM. It can be clearly seen that both $\mathrm{CoSn}(\mathrm{OH})_{6}$ (Fig. 4a-b) and CSNC (Fig. 4c-d) display a uniform morphology of nanocubes, These well dispersednanocubes have diameters of 100-150 nm. Meanwhile, there are no obvious nanocube shapes that can beobserved in CSNC@NC-2 (Fig.4e-f), due to the carbon layer evenly coating the surface of CSNC, so the sizes of CSNC@NC-2 particles have become larger, with diameters of 100-250 nm. The microstructure of CSNC@NC-2 was examined by TEM and high resolution TEM (HRTEM) for further analysis. The images in Fig. 5(a-c) reveal that the CSNC nanocubes were hidden inside the carbon layer, and that the thickness of the carbon layer is well-proportioned with a size of 40-60 nm. An HRTEM image is shown in Fig. 5d, where the lattice spacing of $0.19 \mathrm{~nm}$ is assigned to the (110) crystal planes of $\mathrm{SnSe}_{2}$, and the lattice spacing of 0.29 and $0.26 \mathrm{~nm}$ corresponds to the (110) crystal planes of o-CoSe 2 and the (210) crystal planes of c-CoSe 2 , respectively. Moreover, the elemental mapping images of CSNC@NC-2 in Fig. 5(e-j) confirm the presence of $\mathrm{Co}, \mathrm{Se}, \mathrm{Sn}, \mathrm{C}$, and $\mathrm{N}$ elements, while the uniform distribution of Co and $\mathrm{Se}$ elements illustrates the intimate contact between the two components.

The electrochemical performance of CSNC@NC was investigated by $\mathrm{CV}$ and galvanostatic tests. The first five CV curves are shown in Fig. 6a. There are three cathodic peaks $(1.748,1.513$, and $1.351 \mathrm{~V})$ that appear in the reduction process, which correspond to conversion reactions of $\mathrm{SnSe}_{2}$, and $\mathrm{CoSe}_{2}$ to form $\mathrm{Sn}, \mathrm{Co}$, and $\mathrm{Li}_{2} \mathrm{Se}$, while the peak between 0.01-0.3 V reflects the further alloying reaction of $\mathrm{Sn}$ and $\mathrm{Li}$. Four redox peaks occur in the corresponding reverse process. The peak at $0.563 \mathrm{~V}$ can be due to the dealloying process of $\mathrm{Li}_{4.4} \mathrm{Sn}$, while the decomposition of $\mathrm{Li}_{2} \mathrm{Se}$ takes place at $1.251 \mathrm{~V}$. The last two peaks that appear at 2.079 and $2.320 \mathrm{~V}$ are related to the oxidation of $\mathrm{Sn}$ to $\mathrm{SnSe}_{2}$ and Co to $\mathrm{CoSe}_{2}$, respectively. The reactions occurring in the complete discharge-charge process can be summed up as follows:

$\mathrm{SnSe}_{2}:$ 
$\mathrm{SnSe}_{2}+x \mathrm{Li}^{+}+x \mathrm{e}^{-} \leftrightarrow \mathrm{Li}_{x} \mathrm{SnSe}_{2}$

$\mathrm{Li}_{x} \mathrm{SnSe}_{2}+(4-x) \mathrm{Li}^{+}+(4-x) \mathrm{e}^{-} \leftrightarrow \mathrm{Sn}+2 \mathrm{Li}_{2} \mathrm{Se}$

$\mathrm{Sn}+4.4 \mathrm{Li}^{+}+4.4 \mathrm{e}^{-} \leftrightarrow \mathrm{Li}_{4.4} \mathrm{Sn}$

$\mathrm{CoSe}_{2}$ :

$\mathrm{CoSe}_{2}+x \mathrm{Li}^{+}+x \mathrm{e}^{-} \leftrightarrow \mathrm{Li}_{x} \mathrm{CoSe}_{2}$

$\mathrm{Li}_{x} \mathrm{CoSe}_{2}+(2-x) \mathrm{Li}^{+}+(2-x) \mathrm{e}^{-} \leftrightarrow \mathrm{CoSe}+\mathrm{Li}_{2} \mathrm{Se}$

$\mathrm{CoSe}+2 \mathrm{Li}^{+}+2 \mathrm{e}^{-} \leftrightarrow \mathrm{Co}+\mathrm{Li}_{2} \mathrm{Se}$

Fig. 6b shows the charge and discharge curves of CSNC@NC-2. Note that, the initial discharge capacity can reach $1173.87 \mathrm{mAh} \mathrm{g}^{-1}$, while the first charge capacity can only maintain $804.74 \mathrm{mAh} \mathrm{g}^{-1}$. The $31.44 \%$ irreversible capacity loss is owing to inevitable formation of solid-electrolyte-interphase (SEI) layers. Some plateaus occur in the charge and discharge processes, which consistent with analysis of CV results. It should be noted that the presence of $\mathrm{SnSe}_{2}$ can make the plateau as low as $\sim 0.5 \mathrm{~V}$ during the discharge process. Although the irreversible capacity loss makes the charge capacity of CSNC@NC-2 decay to $766.47 \mathrm{mAh} \mathrm{g}^{-1}$ in the second cycle, very stable cycling performance is exhibited in the subsequent cycle (Fig.6c). The discharge capacity of CSNC@NC-2 can be maintained at $730.41 \mathrm{mAh} \mathrm{g}^{-1}$ after 100 cycles at a current density of $0.2 \mathrm{~A} \mathrm{~g}^{-1}$, and the corresponding coulombic efficiency also remains high above $95 \%$ except for the first cycle. In contrast, the final capacity retention of CSNC, CSNC@NC1, and CSNC@NC-3 is only 323.70, 393.80, and $523.20 \mathrm{mAh} \mathrm{g}^{-1}$, respectively. Meanwhile, the robustness at high current rates was further explored by gradually increasing the current density, every ten cycles from 0.1 to $5.0 \mathrm{~A} \mathrm{~g}^{-1}$ (Fig. 6d). The discharge capacity of CSNC@NC-2 remains stable in each constant current process, and the capacity change is average when the current density increases each time. When the current density is switched back to $0.1 \mathrm{~A} \mathrm{~g} \mathrm{~g}^{-1}$, there is almost no capacity loss compared to the first ten cycles, and the CSNC@NC-2 electrode exhibits a higher capacity than CSNC, CSNC@NC-1, and CSNC@NC-3 throughout the whole process.

Although the cycle performance of the CSNC is not very excellent, it displayed

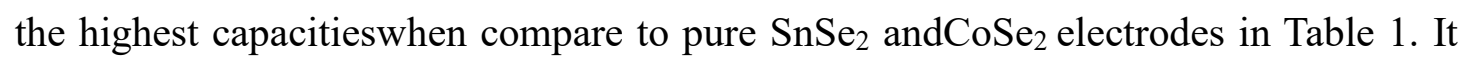


suggests that the combination and interaction of $\mathrm{SnSe}_{2}$ and $\mathrm{CoSe}_{2}$ make CSNC own a better lithium storage ability than those of every individual component.

Electrochemical impedance spectroscopy (EIS) was conducted to further analyze the improved electrochemical performance of CSNC@NC-2. As shown in Fig.7a, the impedance spectra consist of an irregular semicircle in the high tomedium frequency region and a straight line in the low frequency region. It is noteworthy that the charge transfer resistance in the middle frequency range of the semicircle affects the charge transfer process, and it can be estimated by the radius of semicircle. It can be seen tha tCSNC@NC-2 electrode has a lower charge transfer resistance than CSNC, leading to a more excellent electrochemical performance. The linear fitting of the Warburg impedance is shown in Fig. $7 \mathrm{~b}$, where the Warburg coefficient $\left(A_{\mathrm{w}}\right)$ is proportional to the slope of the $Z$ vs. $\omega^{-1 / 2}$ line at low frequency. The valuesof the $\mathrm{Li}^{+}$diffusion coefficient (D) can be estimated from the following equation [38]:

$$
D_{L i^{+}}=0.5\left[\frac{V_{m}}{F S A_{w}}\left(-\frac{d E}{d x}\right)\right]^{2}
$$

These parameters, including $V_{\mathrm{m}}, F, S$ and $(-d E / d x)$ that appear in the above formula are constants for the model test cells, which corresponds to the molar volume, Faraday constant, surface area of the electrode and slope of the open-circuit potential versus the mobile ion concentration $x$ at each $x$ value, respectively [39]. Hence, the $D_{\mathrm{Li}}{ }^{+}$is directly proportional to $\left(1 / A_{\mathrm{w}}\right)^{2}$, and the slope of CSNC@NC-2 is much lower than that of CSNC, indicating that its better ionic conductivity has resulted in an improved electrochemical performance.

The value of $(-d E / d x)$ is difficult to determine, in order to calculate the actual value of $D_{\mathrm{Li}}{ }^{+}$, it can change processing to get the formula as follow:

$$
D=0.5\left(\frac{R T}{n^{2} F^{2} A \mathrm{CA}_{\mathrm{w}}}\right)^{2} \quad \omega \gg \frac{2 D_{\mathrm{L}}}{L^{2}}
$$

Where $\mathrm{R}$ is constant $\left(8.314 \mathrm{~J} \cdot \mathrm{K}^{-1} \cdot \mathrm{mol}^{-1}\right)$, $\mathrm{T}$ is absolute temperature $(298 \mathrm{~K})$, A is the surface area of electrode $\left(1.13 \mathrm{~cm}^{2}\right), \mathrm{n}$ is the charge transfer number, $\mathrm{F}$ is the Faraday's constant $\left(96,485 \mathrm{C} \cdot \mathrm{mol}^{-1}\right), A_{\mathrm{w}}$ is the slope of the $Z^{\prime}$ vs. $\omega^{-1 / 2}$ line, $\mathrm{C}$ is the $\mathrm{Li}$ - 
ion concentration $\left(0.0292 \mathrm{~mol} \cdot \mathrm{cm}^{-3}\right), \mathrm{D}$ is the chemical diffusion coefficient $\left(\mathrm{cm}^{2} \cdot \mathrm{s}^{-1}\right)$. Thus the calculated chemical diffusion coefficient of CSNC, CSNC@NC-1,CSNC@NC-2 and CSNC@NC-3 are 5.82 $\times 10^{-17}, 8.09 \times 10^{-17}, 1.06 \times$ $10^{-16}, 1.97 \times 10^{-16} \mathrm{~cm}^{2} \mathrm{~s}^{-1}$, respectively.

Due to its remarkable behavior in Li storage, the electrochemical performance of CSNC@NC-2 for Na storage was tested with a sodium metal counter electrode. In the cathodic scan of the CV curves (Fig. 8a), the peaks at 1.404, 1.088, and $0.670 \mathrm{~V}$ correspond to the formation of $\mathrm{Sn}, \mathrm{Co}$, and $\mathrm{Na}_{2} \mathrm{Se}$, while the peak positioned at $0.01 \mathrm{~V}$ reflects the further alloying reaction of $\mathrm{Sn}$ and $\mathrm{Li}$ [40]. In the anodic scan, the peak at $1.255 \mathrm{~V}$ can be due to the dealloying process of $\mathrm{Na}_{3.75} \mathrm{Sn}$ [41], while the peak appearing at $1.908 \mathrm{~V}$ is related to the sodium extraction and the oxidation of $\mathrm{Sn}$ to $\mathrm{SnSe}_{2}$, and $\mathrm{Co}$ to $\mathrm{CoSe}_{2}$. In general, the $\mathrm{Na}$ storage and Li storage have similar characteristic, and the different redox potential can be ascribed to thermodynamic origins. During the first cycle (Fig. 8b), the first sodiation capacity is $680.1 \mathrm{mAh} \mathrm{g}^{-1}$. Nevertheless, the formation of the SEI layer results in a reversible desodiation capacity of only 351.5 $\mathrm{mAh} \mathrm{g}^{-1}(51.68 \%)$. Fig. $8 \mathrm{c}$ displays the long cycle testing at a current density of $0.2 \mathrm{~A}$ $\mathrm{g}^{-1}$. The discharge capacity of CSNC is only $41.3 \mathrm{mAh} \mathrm{g}^{-1}$ after 100 cycles, while the final discharge capacity of CSNC@NC-2 can be maintained at $249.5 \mathrm{mAh} \mathrm{g}^{-1}$. There is a slow downward trend that occurs in CSNC@NC-2 electrode during the 100 cycles. This is mainly because the SEI layer on the $\mathrm{Na}$ anode is unstable and evolves during the cycling, causing capacity fading and $\mathrm{Na}$ consumption. Therefore, the cycling performance for Na storage is not as stable as for Li storage. In Fig. 8d, the CSNC@NC2 electrode displays discharge capacity of 347.6, 261.2, 199.4, 148.5, 126.3, and 90.8 $\mathrm{mAh} \mathrm{g}{ }^{-1}$, at the current densities of $0.1,0.2,0.5,1.0,2.0$, and $5.0 \mathrm{~A} \mathrm{~g} \mathrm{~g}^{-1}$, respectively. When it is switched back to $0.1 \mathrm{~A} \mathrm{~g}^{-1}$, the capacity climbs back towards $279.3 \mathrm{mAh} \mathrm{g}^{-1}$, and this durability in rate capabilityis much better than for CSNC. Meanwhile, the CSNC@NC-2 electrode exhibits lower charge transfer resistance (Fig. 9a) and better ionic conductivity (Fig. 9b). The calculated chemical diffusion coefficient of CSNC and CSNC@NC-2 are $1.5 \times 10{ }^{16}, 5.94 \times 10^{-17} \mathrm{~cm}^{2} \mathrm{~s}^{-1}$, respectively. This causes remarkably 
enhanced conductivity and much faster transport of $\mathrm{Na}$ ions, resulting in excellent electrochemical performance.

To better understand the improved cycling performance, SEM images of the CSNC and CSNC@NC electrodes after 100 cycles of Li and Na storages are compared in Fig. 10. It is clear that the CSNC electrode after $\mathrm{Li}^{+}$storage (Fig. 10a) shows many cracks and voids with a rough surface, owing to the volume expansion of nano-particles during cycling. In contrast, the surface of CSNC@NC electrode after Li storage (Fig. $10 \mathrm{~b})$ is smoother than that of CSNC electrode, and the nano-particles are distinguishable. The same phenomenon can be observed after Na storage. The nanoparticles in CSNC electrode (Fig. 10c) stick together in clumps, while this situation does not appear in CSNC@NC electrode (Fig. 10d). It is concluded that the integrity of the electrode material plays an important role in cycling performance.

The superior Li storage and Na storage performances of CSNC@NC-2 ascribed to the conductive carbon coating layer, which provides protective containment with uniform thickness. The CSNC is hidden inside the carbon, easing the expansion of the volume to a certain extent, which retains the integrity of the nanoparticles and avoids the pulverization of the electrode. On the other hand, the carbon layer can protect the electrode from direct contact with the electrolyte, so it guarantees the stability of the SEI, leading to a stable cycling performance.

\section{Conclusions}

In summary, nitrogen-doped carbon (NC) coated $\mathrm{CoSe}_{2}-\mathrm{SnSe}_{2}$ nanocubes were successfully synthesized by an ordinary pyrazole polymerization and carbonization process. This structure is designed to provide sufficient stability for the electrode during cycling, while ensuring fast transport pathways for electrons. When it served asanode for Li storage, the CSNC@NC-2 electrode exhibited the high initial discharge capacity of $1173.87 \mathrm{mAh} \mathrm{g}^{-1}$, stable cycling capacity $\left(730.41 \mathrm{mAh} \mathrm{g}^{-1}\right.$ over 100 cycles at $0.2 \mathrm{~A}$ $\left.\mathrm{g}^{-1}\right)$, and excellent rate performance. Such improved stability was a benefit of the spatial buffering of the carbon layer, so that the volume expansion of nanoparticles was restricted. In Na storage, the discharge capacity could be maintained at $279.3 \mathrm{mAh} \mathrm{g}^{-1}$ over 100 cycles. The lower capacity compared to Li storage maybe caused by the large 
size of $\mathrm{Na}^{+}$ions. After analysis of these tests, it can be stated that nitrogen-doped carbon-coating $\mathrm{CoSe}_{2}-\mathrm{SnSe}_{2}$ composite offers great potential for high-efficiency Li and Na storage.

\section{References}

[1] P.Poizot, F.Dolhem. Energy Environ. Sci. 4(2011) 2003-2019.

[2] J. B.Goodenough, K. S. Park, J. Am. Chem. Soc. 135(2013) 1167-1176.

[3] E. M. Erickson, C.Ghanty, D.Aurbach, J. Phys. Chem.Lett. 5(2014) 3313-3324.

[4] H. G. Wang, S. Yuan, D. L. Ma, X. B.Zhang, J. M.Yan, Energy Environ. Sci. 8(2015) $1660-1681$.

[5] Y. Xiao, M. Cao, ACS Appl. Mater. Inter. 7(2015) 12840-12849.

[6] Y. Li, H. Zhang, P. K. Shen, Nano Energy 13 (2015) 563-572.

[7] N. Mahmood, C. Zhang, H. Yin, Y. Hou, J. Mater. Chem. A. 2(2014) 15-32.

[8] K. He, F. Lin, Y. Zhu, X. Yu, J. Li, R. Lin, M. M. Doeff, Nano Lett. 15(2015) 57555763.

[9] X. Li, Y. Zhao, Q. Yao, L. Guan, Electrochim. Acta. 270 (2018) 1-8.

[10] R. Sun, Q. Wei, Q. Li, W. Luo, Q. An, J. Sheng, L. Mai, ACS Appl. Mater. Inter. 7(2015) 20902-20908.

[11] B. Farbod, K. Cui, W. P. Kalisvaart, M. Kupsta, B.Zahiri, A.Kohandehghan, D.Mitlin, ACS Nano. 8(2014) 4415-4429.

[12] J. Wan, F. Shen, W. Luo, L. Zhou, J. Dai, X. Han, D. Urban, Chem. Mater. 28(2016) 6528-6535.

[13] S. C. Jung, H. J. Kim, J. W. Choi, Y. K. Han, Nano Lett. 14(2014) 6559-6563.

[14] F. Tu, X. Xu, P. Wang, L. Si, X. Zhou, J.Bao, J. Phys. Chem. C. 121(2017) 32613269 .

[15] N. Yabuuchi, K. Kubota, M. Dahbi,S. Komaba, Chem. Rev. 114(2014) 1163611682.

[16] B. Wang, Y. Xia, G. Wang, Y. Zhou, H. Wang,Chem. Eng. J. 309 (2017) 417-425. 
[17] Q. He, K. Rui, C. Chen, J. Yang, Z. Wen, ACS Appl. Mater. Inter.9(2017) 3692736935 .

[18] X. Ou, C. Yang, X. Xiong,F. Zheng, Q. Pan, C. Jin, K. Huang, Adv. Funct. Mater. 27 (2017) 1606242.

[19] H. Liu, H. Guo, B. Liu, M. Liang, Z.Lv, K. R. Adair, X. Sun, Adv. Funct. Mater. 28 (2018) 1707480-1707489.

[20] L. Wang, J. Zou, S. Chen, G. Zhou, J. Bai, P. Gao andH. Li, Energy Storage Mater. 12 (2018) 216-222.

[21] W. Shi, M. Gao, J. Wei, J. Gao, C. Fan, E. Ashalley, E and Z. Wang, Adv Science, 5(2018), 1700602-1700624.

[22] P. Gao, Y. Y. Zhang, L. Wang, S. Chen, Y. Huang, X. Ma, X and Yu, D, Nano Energy. 32 (2017)302-309.

[23] K. Zhang, M. Park, L. Zhou, G. H. Lee, W. Li, Y. M. Kang, J. Chen,Adv. Funct. Mater.26 (2016) 6728-6735.

[24] Z. Zhang, Y. Fu, X. Yang, Y. Qu, Z. Zhang,ChemNanoMat 1 (2015) 409-414.

[25] X. Ou, J. Li, F. Zheng, P. Wu, Q. Pan, X. Xiong, M. Liu, J. Power Sources 343 (2017) 483-491.

[26] W. Yang, J. Wang, C. Si, Z. Peng, Z. Zhang, Nano Res. 10(2017) 2584-2598.

[27] W. Hou, B. Yu, F. Qi, W. Wang, B.Zheng, W. Zhang, Y. Chen, Electrochim.Acta 255 (2017) 248-255.

[28] B. Yu, F. Qi, B. Zheng, W. Hou, W. Zhang, Y. Li, Y. Chen, J. Mater. Chem. A 6(2018) 1655-1662.

[29] Y. Jiang, M. Hu, D. Zhang, T.Yuan, W. Sun, B. Xu, M. Yan, Nano Energy 5 (2014) 60-66.

[30] Z. Hu, Z. Zhu, F. Cheng, K. Zhang, J. Wang, C. Chen, J. Chen, Energy Environ. Sci. 8(2015) 1309-1316.

[31] Y. Liu, M. Zhu, D. Chen, J. Mater. Chem. 3(2015) 11857-11862.

[32] G. D. Park,J.H. Kim,Y.C. Kang, Mater Charact. 120 (2016) 349-356.

[33] D. H. Liu, W. H. Li, Y. P.Zheng, Z. Cui, X. Yan, D. S. Liu, J. Z.Guo, Adv. Mater. 30(2018) 1706317. 
[34] K. Chang, Z. Wang, G. Huang, H. Li, W. Chen, J. Lee, J. Power Sources 201 (2012) 259-266.

[35] W. Chen, Y. Liu, Y. Li,J.Sun, Y. Qiu, C. Liu, Y. Cui, Nano Lett. 16(2016) 75887596.

[36] H. Li, X. Qian, C. Zhu,X. Jiang, L. Shao, L.Hou, J. Mater. Chem. A 5(2017) 45134526 .

[37] K. Zhou, J. He, X. Wang, J. Lin, Y. Jing, W. Zhang, Y. Chen, Electrochim. Acta 231 (2017) 626-631.

[38] W. Wang, Y. Yang, S. Yang, Z. Guo, C. Feng, X. Tang, Electrochim. Acta 155 (2015) 297-304.

[39] S. Xu, L. Lu, X. Jiang, Z. Luo, K. Liu, G. Li, C.Feng, J. Appl.Electrochem. 46(2016) 279-287.

[40] X. Xie, D. Su, S. Chen, J. Zhang, S. Dou, G. Wang,Chem-Asian J. 9 (2014) 16111617.

[41] Y. Liu, H. Kang, L. Jiao, C. Chen, K. Cao, Y. Wang, H. Yuan, Nanoscale 7(2015) $1325-1332$.

[42] Z. X. Huang, B. Liu, Dezhi. Kong, Y. Wang, H. Y. Yang, Energy Storage Mater10 (2018) 92-101.

[43] D. H. Lee,C. M. Park,ACS Appl.Mater. Inter. 9(2017)15439-15448.

[44] J. Choi,J. Jin, I. G. Jun, J. M. Kim, H. J. Kim, Chem.Commun. 47 (2011) 5241 5243.

[45] C. F. Du, J. R. Li, X. Y. Huang,RSC Adv. 6 (2016) 9835-9842.

[46] Z. P. Li, H. T. Xue, J. Q. Wang, Y. B. Tang, C. S. Lee, S. R. Yang, Chem. Electrochem. 2 (2015) 1682-1686. 
Fig.1 XRD patternsfor (a) CoSn $(\mathrm{OH})_{6}$, (b) CSNC and CSNC@NC.

Fig. 2(a) Raman spectra of CSNC and CSNC@NC, (b) TGA curves of CSNC and CSNC@NC.

Fig. 3 XPS spectra of CSNC@NC-2: (a) survey spectrum, (b) Se 3d, (c) Co 2p, (d) Sn 3d, (e) C 1s, and (f) N 1s.

Fig. 4 SEM images of (a-b) $\mathrm{CoSn}(\mathrm{OH})_{6}$, (c-d) CSNC, and (e-f) CSNC@NC-2.

Fig. 5 TEM images of (a-e) CSNC@NC and (f-j)corresponding elemental mapping images.

Fig. 6 Electrochemical Li storage: (a) CV curves of CSNC@NC-2; (b) Discharge/charge voltage profiles of CSNC@NC-2; (c) Cycling performance of CSNC and CSNC@NC; (d) Rate performance of CSNC and CSNC@NC.

Table1Cycling performance of CSNC compared to pure $\mathrm{SnSe}_{2}$ and $\mathrm{CoSe}_{2}$ electrodesas lithium anode.

Fig. 7 Li storage kinetics: (a) Impedance spectra of CSNC and CSNC@NC; (b)Linear fitting of Warburg impedance of CSNC and CSNC@NC.

Fig. 8 Electrochemical Na storage: (a) CV curves of CSNC@NC-2; (b) Discharge/charge voltage profiles of CSNC@NC-2; (c) Cycling performance of CSNC and CSNC@NC-2; (d) Rate performance of CSNC and CSNC@NC-2.

Fig. $9 \mathrm{Na}$ storage kinetics: (a) Impedance spectra of CSNC and 
CSNC@NC-2; (b)Linear fitting of Warburg impedance of CSNC and CSNC@NC-2.

Fig. 10 SEM images of working electrode after 100 cycles. For Li storage:

(a) CSNC, (b) CSNC@NC-2; For Na storage: (c) CSNC, (d) CSNC@NC2 
